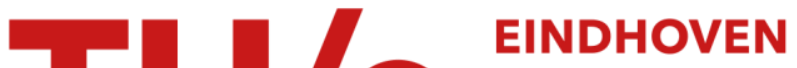 UNIVERSITY OF TECHNOLOGY
}

\section{Wireless network simulation - Your window on future network performance}

Citation for published version (APA):

Fledderus, E. (2005). Wireless network simulation - Your window on future network performance. Wireless Personal Communications, 33(3), 319-325. https://doi.org/10.1007/s11277-005-0575-0

DOI:

10.1007/s11277-005-0575-0

Document status and date:

Published: 01/01/2005

Document Version:

Publisher's PDF, also known as Version of Record (includes final page, issue and volume numbers)

Please check the document version of this publication:

- A submitted manuscript is the version of the article upon submission and before peer-review. There can be important differences between the submitted version and the official published version of record. People interested in the research are advised to contact the author for the final version of the publication, or visit the $\mathrm{DOI}$ to the publisher's website.

- The final author version and the galley proof are versions of the publication after peer review.

- The final published version features the final layout of the paper including the volume, issue and page numbers.

Link to publication

\section{General rights}

Copyright and moral rights for the publications made accessible in the public portal are retained by the authors and/or other copyright owners and it is a condition of accessing publications that users recognise and abide by the legal requirements associated with these rights.

- Users may download and print one copy of any publication from the public portal for the purpose of private study or research.

- You may not further distribute the material or use it for any profit-making activity or commercial gain

- You may freely distribute the URL identifying the publication in the public portal.

If the publication is distributed under the terms of Article 25fa of the Dutch Copyright Act, indicated by the "Taverne" license above, please follow below link for the End User Agreement:

www.tue.nl/taverne

Take down policy

If you believe that this document breaches copyright please contact us at:

openaccess@tue.nl

providing details and we will investigate your claim. 


\title{
Wireless Network Simulation - Your Window on Future Network Performance
}

\author{
ERIK R. FLEDDERUS
}

TNO Information and Communication Technology, P.O. Box 5050, 2600 GB, Delft, The Netherlands; TU Eindhoven, Faculty of Electrical Engineering, P.O. Box 513, 5600 MB, Eindhoven, The Netherlands

E-mail: e.r.fledderus@telecom.tno.nl

\begin{abstract}
The paper describes three relevant perspectives on current wireless simulation practices. In order to obtain the key challenges for future network simulations, the characteristics of "beyond 3G" networks are described, including their impact on simulation.
\end{abstract}

\section{Introduction}

Simulation is a standard method in the toolkit of modern engineers; before a piece of equipment, a car or a telecom network is build, it is tested in a computer model that reflects both the object that is tested as well as its surroundings. The aim of this paper is to describe the main challenges for radio network simulators in the context of a "beyond 3G" scenario. After an elaboration on the current practices around simulation in the design of radio systems and networks, the paper concentrates on the characteristics of the "beyond 3G" scenario, and the challenges it poses to radio network simulators.

\section{Different Perspectives on Simulation}

To describe the current practices in simulation, its best to ask the three questions "who/where", "what" and "why". The first question determines the perspective, and in this paper this perspective ranges from vendor, via public network/service operator to private network operator. Now one operator can be very different from another one, e.g. in its involvement in development and standardisation of new radio technology. Hence, answering the first question is not enough to single out a number of key objectives that are approached with simulation. For that, the image of e.g. operator is narrowed down, so the question "what is simulated and for what purpose" can be answered more decisively.

\section{Vendor PERSPECTIVE}

New standards and improvements of current standards need careful preparation. Broadly speaking, the phase that concentrates on a decision for a concept layout of the technology is followed by a phase where optimisation plays a central role. Of course, these phases can be part of a re-iteration process, where parts of the concept are adapted after a first round of simulations. 


\section{Examples include}

- The use of a pre-amble to train the receiver, with the length of the pre-amble subject to optimisation, based on the signal processing algorithm in the receiver. The simulations that are used for this optimisation usually don't take the complete system into account, but concentrate on e.g. the PHY layer. And to make results comparable between different vendors, a number of channel models are defined, mirroring reality.

- Different approaches to mitigate RF impairments, like I-Q mismatch, phase noise and amplifier non-linearities (see e.g. [1, 2]). Although simulations in this area are quite successful to study a single type of impairment, intelligent combinations of modelling and simulation are required to be able to grasp the full picture and to obtain an integral model that contains a substantial number of these impairments - the use of simulations can be overestimated.

The two examples, though perhaps oversimplified, contain a few clear take-aways:

- To analyse options, a "black box" approach is required to parts that are beyond the scope of the analysis (channel model, TCP/IP, mapping between channel quality and perceived service quality, etc.)

- To obtain an integral understanding of e.g. system performance that includes multiple parameters, simulations alone will not do, but instead a combination of advanced modelling supported by simulations [3].

- The vendor perspective, narrowed down to inventing and developing new technology, has taken limited attention of the network performance.

\section{The Mobile Operator Perspective}

Most mobile operators have embraced simulations only rather recently. Although clearly present at the dawn of 2 nd generation mobile systems, their involvement in the development of $3 \mathrm{G}$ mobile technology and WLAN systems have clearly decreased. This shift has not been caused by the more difficult financial position of mobile operators, but by a shift in the role and attention towards a service operator that happens to own a network. Therefore, the objective of simulations at mobile operators focus more on the judgement and proper deployment of new technology, and its impact on the (user perceived) service quality, than on the development of this technology per se. Examples include

- The assessment of features that are included in a new release, like frequency hopping, fractional loading and dynamic frequency assignment in GSM [4]. It is striking that for all these features the vendors had performed simulations, showing clearly the benefit of each. Apparently, this was not sufficient - so what is it that is/was added by the operators?

$\Rightarrow$ First of all, the sensitivity of the improvement to changes in the inputs of the simulations is not always clear. That is, realistic conditions may reveal a different (usually smaller) gain as was predicted by the (vendors') simulations. This usually calls for a pilot, but in certain cases specific network simulations are performed with realistic settings for traffic and interference conditions.

$\Rightarrow$ Secondly, deciding on buying or enabling a feature is always part of a business case. An example that currently attracts quite some attention is remote electrical downtilt that is quite promoted, e.g. by vendors of optimisation tools [4]. This business case involves besides technical simulations also an assessment of the optimisation process and the rollout and planning strategy and guidelines of an operator. Clearly there is something to add 
by the operator - and when it involves simulations, the scope is usually complementary to that of the vendors and focussed on the proper input for the business case [5].

- Examination of "what-if" scenarios. This aspect was not so much an issue for European operators, but much more for American operators due to the strong technology competition around $2 \mathrm{G}$ mobile systems. Though the chapter on future perspectives will elaborate on how this technology competition has also manifested itself in the European operator arena, at this point it is clear that operators want to able to consider different solutions and their advantages and disadvantages, e.g. given a number of traffic scenarios, predictions of user requirements, spectral regulations, etc.

- Trouble-shooting of problem areas. The trigger for analysing a weak spot in the network is usually a series of user complaints. When no element alarms are obtained, the problem may be caused by a combination of circumstances. This calls for an integral model of the network, where network behaviour is coupled into services behaviour and this into user perception, and where each layer is modelled to a certain level of detail, in order to capture the complaint and its origins.

Also these examples lead to a number of new conclusions on the use and importance of today's simulation practices:

- In order to capture e.g. realistic traffic and propagation conditions, most operators perform a pilot. The possibility of using channel and traffic measurements in simulations has lowered the aversion of operators to clean-cut simulations.

- The operator perspective clearly puts forward the integral approach to performance evaluation and optimisation. This comprises both the radio and the core network, up to e.g. the GGSN, and from the PHY layer to the application layer, and the user perception.

\section{The Private Operator Perspective}

Besides the public (mobile) operators, the introduction of dedicated networks has spawned private network operators. Examples are the GSM-rail, TETRA, and WLAN hot spot operators, and military networks. Most of these operators ask for turn-key solutions from their vendors, hence the need for simulations is more or less absent. The defence departments are an exception to this rule. Since they want to be sure that their networks can be operated in extreme conditions, they run extensive network simulations to prove this [6]. Like with the public mobile operators, testing equipment under realistic and extreme conditions is the major perspective shift compared to standard simulations. This perspective adds the following conclusion to the previous ones:

- The use of parallel computing for radio network simulation is still in its infancy, especially when compared to other industries (oil, weather, chemistry) [7].

\section{Future Perspective on Simulation}

To sketch a future perspective on simulation in "beyond 3G" networks, its important to start with defining what is meant with "beyond 3G". This is done at the hand of four concepts that are thought to be characteristic for "beyond 3G" networks. After introducing each concept, its impact on network simulation is described. 


\section{INCREASED TECHNOLOGY COMPETITION}

The current situation in the telecom industry is one of a strong technology competition. The certainties that characterised the GSM-era in Europe are more or less over. Although it is difficult to predict which technologies will prevail in the long run, most experts agree on a hybrid network that consists of a number of layers, ranging from satellite networks to pico-cells and spontaneous networks. On of the key challenges for this type of network is to ensure an efficient radio resource management, since this is the sole reason for having the different layers in the long run: certain networks can provide a particular service more efficiently than others. Hence based on service and user requirements, and the options (networks) available, the RRM functionality decides the most suitable network. In addition, when users move throughout the network, radio conditions change as do the available networks, e.g. when moving from the indoors to outdoors. Especially from the operator perspective is desirable to simulate network interoperability and the more specifically the service performance during so-called vertical handovers.

Note that UMTS networks from this point of view are already quite challenging. First of all, at service request, the session needs to be mapped on the most adequate radio bearer, and during changing radio conditions rate switching may be evoked, enforcing the session to be mapped on a bearer with a different - often lower - bit rate (see e.g. Figure 1, taken from the IST project MOMENTUM [8]).

\section{The User as a Micro Network}

Another trend is clearly visible at the terminal side. With the ability to switch between different networks, the terminal will also be able to connect to thin clients in its physical neighbourhood,
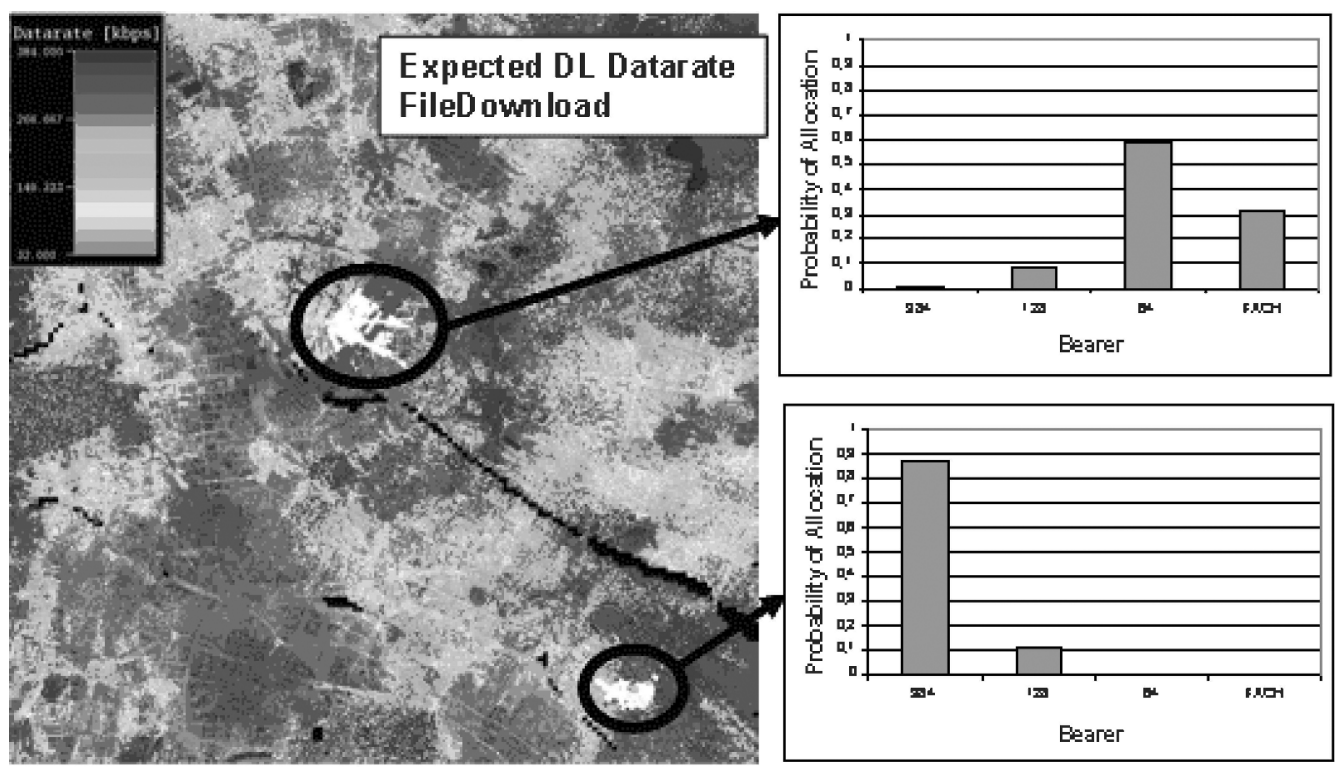

Figure 1. Expected downlink data rate and the probability that a certain bearer (rate) is allocated, based on network simulations for the city of Berlin. 


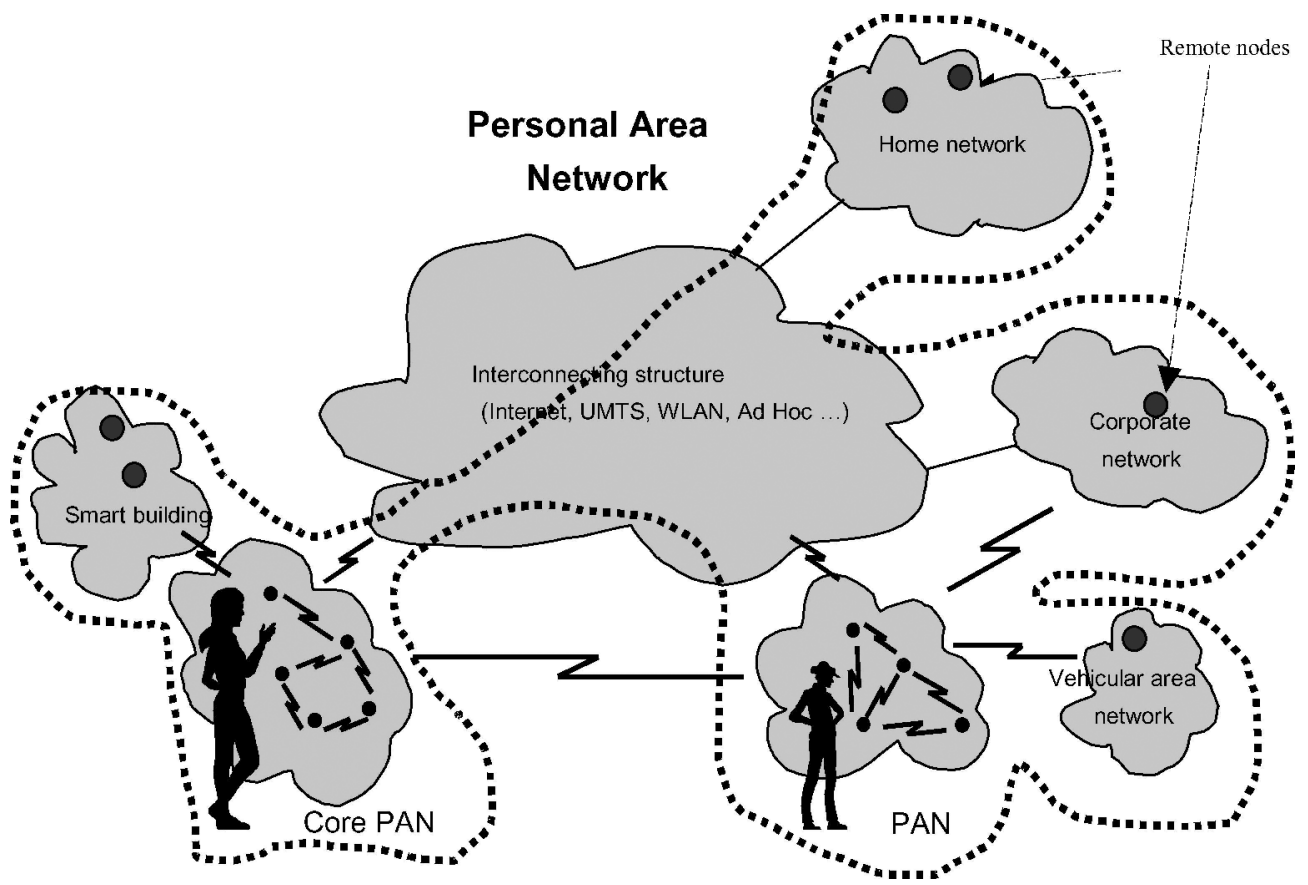

Figure 2. A graphical impression of the personal area network concept; the user in the left lower corner is connected to other localised networks, e.g. a vehicular network in a car.

and, via the network, to other devices and (known) servers. This vision has been materialised in the concept of Personal Area Network ([9], see Figure 2 ).

The effect on network simulations is that the terminal concept, the associated customer behavioural model and the data that is produced needs a drastic update. Customer behaviour may be captured in use cases that are attached to a certain location. In this way office users require a printer service a number of times per hour, thereby downloading the document via the corporate WLAN network and using an ultra wideband connection to upload the retrieved document to the printer.

\section{INTEgRAL APPROACH TO PERFORMANCE}

Current GPRS and UMTS networks show that improving the performance of data services requires a thorough understanding of more than only the radio link or the core network. Optimising part of the transmission chain will reveal suboptimal solutions, and a combination of suboptimal solutions may even worsen the performance. Combined with a multi-radio network, an integral approach to performance may turn out to be extremely demanding from a computational point of view. Therefore, developing a so-called ghost module of (parts of) a network, representing a simplified though adequate version of this network, will enable a speed-up of the simulations.

\section{Conclusions}

Based on a number of trends in wireless communications that constitute the basics of future "beyond 3G" networks, the paper has identified a number of challenges for future wireless 
network simulations:

- Realistic implementations of the multi-radio resource management and interoperability functionality

- Improved user behaviour and service modelling, reflecting the concept of the personal area network.

- Development of simplified and adequate simulation modules of wireless networks or parts of it, including a proper interface.

\section{References}

1. T.C.W. Schenk and A. van Zelst, "Frequency Synchronization for MIMO OFDM Wireless LAN Systems," in Proc. IEEE Vehicular Technology Conference Fall 2003 (VTC Fall 2003), Orlando (FL), Oct. 2003, Vol. 2, pp. 781-785.

2. T.C.W. Schenk, X.-J. Tao, P.F.M. Smulders, and E.R. Fledderus, "Influence and Suppression of Phase Noise in Multi-Antenna OFDM," in Proc. IEEE Vehicular Technology Conference Fall 2004 (VTC Fall 2004), Los Angeles (CA), pp. 26-29 Sept. 2004.

3. E.R. Fledderus, "Mathematical Modelling in the UMTS Planning Process: The Concept of Effective Bandwidth," in Proc. of "Workshop on IP and Related Issues to UMTS/IMT-2000, Aalborg University, August 2000.

4. T. Neubauer, "Achieving Rapid 3G Capacity and Coverage Enhancement Through Automated Antenna Optimization Techniques," Cell Planning Conference, Prague, 2004.

5. E.R. Fledderus, M. Rijken, and J.C. van der Wal, "Remote Electrical Downtilt", TNO Telecom report no 33530, 2005.

6. B. Boltjes, I.F. Fernandez, B.A. Kock, R.J.G.M. Langeveld, and G. Schoenmaker, "Validation and Adaptation of Router and Switch Models," in Proc. of the Conference OPNETWORK, 26-30 August 2002, Washington, DC.

7. M.J. Fleuren, H. Stüben, and G.F. Zegwaard, "MoDySim - A parallel Dynamic UMTS Simulator", in Proc. of PARCO 2003, Dresden.

8. IST-MOMENTUM, http://momentum.zib.de.

9. Paper from Ignas Niemegeers in this issue.

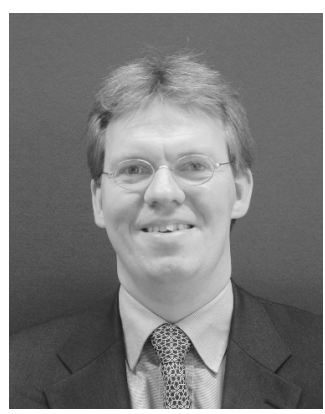

Erik Fledderus (1970) received a PhD in Applied Mathematics in 1997, after which he started working at KPN Research, which merged with TNO in January 2003. He developed the basis for UMTS radio network planning at KPN, and initiated in 2000 a European project proposal, Momentum, in the area of UMTS radio planning and simulation, with 7 partners from Germany and Pottugal. Erik acted as project leader and co-ordinator from 2001-2003. Also at the end of 2000 he initiated together with Eindhoven University of Technology, Agere Systems and Philips Research a research proposal in the area of antenna arrays and MIMO in 
WLAN and UMTS. One of the results of this project lies at the basis for the 802.11n-proposal by Agere/Philips.

Since March 1st 2003, Erik is part-time professor at Eindhoven University of Technology in the field of Wireless Communication Networks.

Within TNO he is senior strategist, program manager of the program Future ICT Architectures, and leading in the knowledge management regarding radio and mobile network technology, and strategist on mobile/wireless technology in general. 